\title{
Application of Network Information Technology on Physical Education Training System
}

\author{
Wei Liu \\ Hunan Vocational College of Modern Logistics, Changsha, Hunan, 410131
}

Keywords: network information; physical education; training system

\begin{abstract}
Due to the wide variety of sports videos and the similarity of sports videos, this paper takes shot-putting video as a research point, and also has certain reference significance for the analysis of other videos. Shooting shot-putting, video transmission and preservation of the network, and digital analysis of the video image are to get shot trajectory, shot angle and direction of movement and data release. This paper focuses on technical testing and practical research, and does not make a major explanation on the tracking of shot distances. The feasibility of the combination of computer vision and sports videos, the process development, the real-time results and the feasibility of system integration are discussed.
\end{abstract}

\section{Introduction}

Advanced computing and application technology, China's computing and application technology is currently developing to high performance, high cost performance, and better support for the latest applications in the network environment. The development of computing and application technology is a long-term process. Overall, based on the existing applications, China's computing technology is closely following the mainstream of international computing technology development, focusing on independent innovation, and has made gratifying breakthroughs in multiple technologies and applications. The development of major application computing systems in China focuses on three aspects of development. Develop needs for financial, internet, medical, and stylistic industry applications. The development of high-capacity, low-power, high-availability, and practical information systems has made great strides in achieving capacity, complexity, and energy consumption. High-end software and its application systems are currently the focus of development, satisfying the needs of computationally-intensive, data-intensive, and service-intensive applications as the starting point, meeting the needs of socialist modernization, meeting the needs of social and public security, monitoring, scientific and technological analysis, and social markets. The huge demand for application systems such as management and intelligent demand. The development of computing and application technologies provides strong support for video technology.

\section{The Role of Information Technology in Learning Sports}

The development of information technology is reflected in the use of electronic computer technology, intelligent control technology, modern communication technology, and remote sensing technology to enable various information to be acquired, transmitted, stored, displayed, and applied. This provides highly advanced learning for school sports. Resources and Teaching Technology. By optimizing the physical education environment, promote teacher-student exchange and interaction, improve students' ability to analyze and solve problems, thereby promoting the improvement of teaching quality.

Due to the shared and interactive nature of information technology, the explanations, demonstrations, operating methods, and assessment feedback in the teaching process have been improved, which has resulted in an optimized and upgraded teaching environment and improved teaching quality. At the same time, due to the characteristics of interactive and interactive information technology, large amounts of resources, and various forms, it has stimulated students' interest in training and their desire to increase students' cooperation and interaction. This has 
promoted the interaction between teachers and students and created good results. Study and exercise atmosphere. Modern information technology emphasizes the integration of various kinds of knowledge. School physical education can be combined with the teaching of other disciplines to assist physical education and exercise. It stimulates students to analyze and solve problems when they encounter problems, so as to improve students' ability to analyze and solve problems. .

Physical training is very much about whether or not the training method is scientific. Modern information technology provides us with a very convenient way to obtain information. Therefore, combining other relevant knowledge, according to the individual information of students or athletes to develop a suitable mathematical model of movement and selection criteria, so as to help students or athletes to achieve better learning And training effectiveness [1].

The previous physical education management needs to be completed in strict accordance with the methods of handing in, periodic review, and temporary spot checks so that the various teaching plans can be completed on time. This leads to heavy burden on sports managers and poor management results. Through the establishment of information systems, computerized network management can be adopted, which not only greatly reduces the burden on managers, but also improves the efficiency of sports management. At the same time, through the development of appropriate computer management software and campus networks, it can not only improve the standardization and high efficiency of sports grounds, funds and equipment management, but also supervise the funds for school sports management, and promote the financial management of schools. The modernization of the system makes it rigorous and transparent. Through the application of information technology in sports management, various auxiliary managements can be conducted in a standardized, rational and efficient manner, and the overall scientific management of sports management is improved.

\section{The Practical Application of Information Technology in Sports}

Due to the performance characteristics of multimedia images and audio, teachers can inspire students' learning enthusiasm and expand their horizons by presenting teaching materials on multimedia. Such as playing some sports games video, and with the teacher's explanations and student interaction, some of the details of the need to pay attention to sports and difficult to explain carefully, in the case of students in the classroom have a very high degree of enthusiasm, the teaching effect can naturally be It has been greatly improved. In the information age, the pace of knowledge renewal is very fast, and the development of science and technology is also very rapid. Various disciplines infiltrate each other. The sports theory itself integrates the theoretical knowledge of different disciplines, and when the relevant subject knowledge is updated rapidly, the sports theory knowledge is also updated [2]. Therefore, the school front-line physical education teachers, coaches, and sports researchers must constantly update and learn knowledge, and Consciously accept reeducation. However, due to the heavy workload, they cannot fully participate in the school system to participate in further studies. However, in the advanced information age, it is very easy to establish a sports network and conduct distance education. For example, in the school sports website to develop corresponding procedures to establish an online learning room, teacher-student exchange platform, teaching media library and test database, so that teachers and students can learn and research through the Internet anytime, anywhere.

When calculating school sports scores and planning school sports work, it is often necessary to deal with a large amount of data. In this case, the use of computers and the development of related systems can be handled very accurately and quickly. For example, using the score management system can automatically generate student scores and statistics; and teachers only need to enter the student's student number and the original test results in the system, the system can complete the automatic scoring check, summary, average score calculation, determine the performance level And so on, such an automated computer processing method has greatly reduced the work intensity of teachers, coaches and sports managers at all levels, and greatly improved the efficiency of work. Under normal circumstances, the distribution of school sports venues on the campus is relatively dispersed, and its management model is also decentralized, which has caused many management 
inconveniences. The management of school sports requires that, under the premise of following the basic laws of sports, all work in school sports should be planned, implemented, and evaluated with the minimum human, material, and best methods. At present, college sports management focuses on sports teaching management, network information management, sports data management and other aspects. In the school sports management work, sometimes it will be necessary to deal with a large amount of calculations, this time can develop the appropriate database software to enable accurate and rapid completion of data processing; also through the computer-related functions, the need for school sports management work The processed data are classified, arranged, ranked, processed, archived to improve the efficiency and orderliness of daily information management.

The sports training of general sports includes the following steps: initial planning, establishment of training objectives, development of relevant training plans, implementation of training and completion of training according to plans, and achievement of training objectives. These links also exist in the traditional school sports training. However, due to irrational reasons in many details, it is difficult for athletes to improve their training performance and the achievement of training goals is not satisfactory. Once combined with computer network technology, these details can be well overcome, and the overall training and rationality of the training can also improve the athlete's training performance can be significantly improved [3]. For example, through the development of relevant database systems, the athlete's daily training plan, implementation status, psychological status and other data are recorded and saved. Based on these data, combined with relevant theoretical knowledge and scientific research methods, a scientific and reasonable and in line with the athletes individual situation is developed. Training plan, training objectives and training methods.

Today is an era of information explosion. Information is productivity. Access to information is of vital importance to almost any company. The development of information technology is mainly reflected in the transformation of network technology. The network has all the functions of traditional media, and has the characteristics of fast information dissemination and new content updates. In school sports, relevant information is collected through the Internet to provide new ideas, concepts and methods for teaching, training and management. Some sports websites publish many information in this regard, report the latest achievements of related projects in real time, and professional professionals comment on certain aspects through the website, and the changes in related sports facilities and venues can also be queried online. Out of this, this is undoubtedly a good thing for teaching and training [4].

Due to the backwardness and tradition of management thoughts, it is difficult for colleges and universities to apply information technology comprehensively in sports management. Therefore, changing the traditional ideas of managers is the primary task. Colleges and universities can strengthen the promotion of information technology, promote management personnel to fully recognize the importance and effective role of information technology in sports management, increase their awareness, and then promote their practical application of information technology. When colleges and universities begin to apply information technology in sports management, they should strengthen the introduction of relevant equipment software, and pay attention to mutual support and coordination, so that on the one hand it can promote the further development of related industries in college sports management [5]. On the other hand, it is also possible to better align the management model with the society, which is more consistent with the market's standardization requirements and ensure the quality of management. It should be noted that universities and colleges need to increase their capital investment in this area based on their own actual needs and conditions, ensure that the hardware equipment for sports management can meet management requirements, and better implement various management measures. Since information technology is in an evolving state, in order to avoid new problems in the process of technology updating, it is necessary to further improve and optimize the traditional management model according to the state of development of information technology, and it may appear that in the course of development, The problems were formulated as emergency measures and they were analyzed in depth to effectively promote their better development. 


\section{Conclusion}

In general, the application of information technology in college sports management is an inevitable trend of scientific development and teaching reform. It can improve the level and quality of sports management. In the actual application process, it is necessary to formulate corresponding normative standards and improve the standardization of management. In order to fully play out the good role of information technology.

\section{References}

[1] Du Yun. Use of information technology to promote the scientific management of school sports [J]. Fujian Computer, 2008(11):28-30

[2] Zheng Min, Yuan Yuan. The role of information technology in school sports application [J]. Sports Journal of Adult Education, 2009(03)77-79

[3] Yang Wenyun, Ma Guoqiang, Yu Jianfeng, Lin Ping. Modern information technology in school sports Application in China [J]. Journal of Hebei Institute of Physical Education, 2008(04):116-118

[4] Zhao Li. Application and Development of Sports Information Technology [J]. Journal of Beijing University of Physical Education,2010(09):102-105 